\title{
Characteristics and driving factors of thermal stratification evolution in Daheiting Reservoir
}

\author{
Liu Chang ${ }^{1}$, Wang Shiyan ${ }^{1}$, Wang Liang ${ }^{1}$, Liu Xiaobo ${ }^{1}$, Zhou Huaidong $^{1}$, Li Budong ${ }^{1}$, Du Yanliang ${ }^{1}$ \\ ${ }^{1}$ State Key Laboratory of Simulation and Regulation of Water Cycle in River Basin, China Institute of Water Resources and Hydropower \\ Research, Beijing, 100038
}

\begin{abstract}
Thermal stratification which is common in water bodies is subject to such factors as the water depth of the water body (a lake or reservoir, for instance), the fluidity of the water and the local meteorological conditions. The stable thermal stratification in reservoirs will lead to changes in the physical and chemical properties of the water as well as distribution of aquatic creatures, hence leaving an impact on the water quality. The Daheiting Reservoir was taken as the research object in this study. Based on the continuous monitored water temperature data in the reservoir, the tempo-spatial change features of the water temperature structure in the reservoir were analyzed, and the driving factors of thermal stratification in the reservoir was studied. The research found that air temperature, wind speed, and hydrodynamic factors are the driving factors for the thermal stratification and corresponding water temperature change patterns in Daheiting Reservoir. Among these factors, air temperature is the fundamental precondition, the wind speed is the auxiliary precondition, and the hydrodynamic factors are the disturbance factors for thermal stratification in the Reservoir. All these factors act together to cause the thermal stratification pattern and evolution features in Daheiting Reservoir.
\end{abstract}

\section{Research background}

Thermal stratification, a common feature of water ecosystems, plays an important role in changes of water quality and water properties in lakes and reservoirs. The major cause of thermal stratification is the temperature difference between the upper layer and the lower layer of the water body, and it is prevalent in lakes and reservoirs [1]. The temperature on the surface of reservoirs present cycling features, which results from heat transfer between the air and the water as well as the seasonal changes of meteorological parameters. The water temperature at the bottom of the reservoir only changes in the autumn and winter with the surface water temperature, but in other months, the temperature changes differ from the upper layer to the lower layer of the reservoir. This is because the bottom receives far less solar radiation than the surface water, and as the depth increases, the disturbance diffusion effect caused by wind cannot reach the bottom water. As a result, the high-temperature water on the surface cannot join the bottom water, while heat transfer at the molecular level is very limited (it was reported that heat transfer at the molecular level is slow and takes about a month to realize $1 \mathrm{~m}$ vertical transfer of heat [1]). Thus, the water temperature at the lower layer of the reservoir shows less changes than that on the surface layer. During thermal stratification, the warm surface of the water body is referred to as epilimnion; the layer with colder water that cannot enter the epilimnion and shows stable temperatures is called hypolimnion. The layer in between that features a large gradient of temperature changes is called the thermocline.

Studies on thermal stratification in reservoirs globally focus more on the pattern, the mechanism and driving factors of thermal stratification as well as quantitative evaluation of thermal stratification. The division of the three layers in thermal stratification was not defined in the initial research stage, and in 1957, Hutchinson [2] divided the layers of water with $1 \mathrm{~km}^{-1}$ as the temperature gradient. Bo-Ping et al. [3] probed into thermal stratification in the SAU Reservoir in Spain, and insisted that the thermal stratification was a result of the joint effects of external forces and internal variables. Boehrer et al. [1] analyzed the water temperature structure of Goitsche Lake in Germany, and identified air temperature as the major contributor to thermal stratification. Champman et al. [4] insisted that the difference between the temperature on the surface and the bottom of the reservoir led to vertical differences of water intensities, which led to the formation of the epilimnion, thermocline and hypolimnion from the surface to the bottom of reservoirs.

Reservoirs are different from lakes in multiple ways. Ford [5] argued that the compared with the situation in lakes of the similar morphology, the water in reservoirs stay for a shorter time due to the inflow and discharge of water of the reservoir. Some think that the thermal stratification in reservoirs is significantly affected by the temperature of the water inflow [6-10]. In terms of stability of thermal stratification, researchers abroad proposed multiple indices for quantitative assessment. Horne and Goldman [11] proposed the TSI index, which 
has been widely used because of its simple calculation. Imberger and Hamblin [2] proposed the Wedderburn number to quantify the mixture stability; Imberger [13] put forward the Lake Number, which was used by Hondzo and Stefan [14] to describe the dynamic stability of the water in reservoirs. Other indices, such as the stability index proposed by Schmidt [15] and the stability index put forward by Hutchinson [2] have also been widely used. These indices have played a significant role in evaluating the stratification tensity, the physical state and features of lakes. During thermal stratification, the thermocline is the key region for division of the thermal layers, and many research results have been achieved in this regard. For instance, Gorham and Boyce et al. [16] argued that the depth of the thermocline was subject to the size and transparency of the lake; Fee et al. [17] thought that as the area of the lake increased, the depth of the seasonal thermocline increases with the increased wind force. Snucins and Gunn [18] argued that the climatic changes also played a role in determining the depth of the thermocline in lakes.

In this study, the Daheiting Reservoir which is the source of the water diversion project from Luanhe River to Tianjin city was taken as the study case. Specifically, the monitored continuous water temperature data in the reservoir were used to analyze the spatio-temporal change features of the water temperature structure in the reservoir, and to figure out the driving factors for the thermal stratification in the reservoir in combination with the surveyed meteorological and marshalling data.

\section{Introduction to the study area and research methods}

\subsection{Introduction to the study area}

The water diversion project from Luanhe River to Tianjin city is situated in on the main stream of Luanhe River

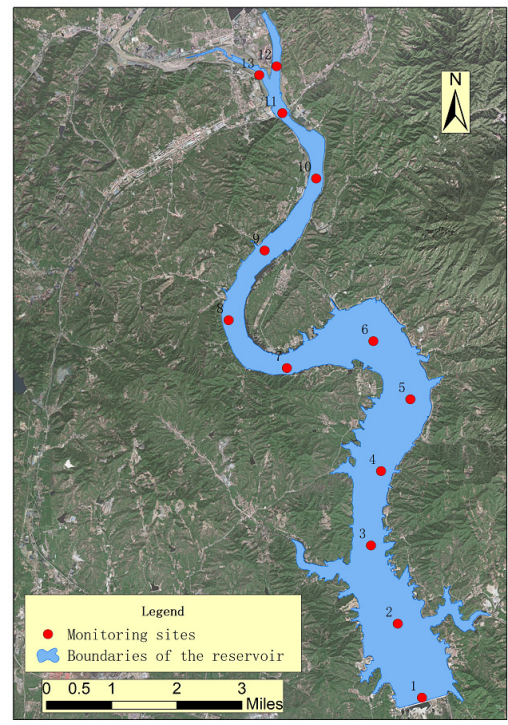

Regular measurement sites within Qianxi county, Tangshan City in Hebei. It consists of large water conservancy projects that develop the water resources of Luanhe River and realize inter-basin water supply for Tianjin, Tangshan, and other cities in the lower reach of Luanhe River. Daheiting Reservoir is a central water conservancy link in this water diversion project. The reservoir is $30 \mathrm{~km}$ away from Panjiakou Reservoir on the mains stream of Luanhe River, and is $5 \mathrm{~km}$ away from Qianxi County on the north, and the basin between Panjiakou Reservoir and Daheiting Reservoir covers an area of $1400 \mathrm{~km}^{2}$. The total capacity of the reservoir is 337 million $\mathrm{m}^{3}$, the water inflow stretches $23 \mathrm{~km}$, and the normal water storage height is $133 \mathrm{~m}$. It is a Level-II water conservancy project of China, and the regulation function is annual regulation.

\subsection{Research methods}

In order to study the temporal and spatial characteristics and driving factors of the thermal stratification of the reservoir, this study employed the portable water quality monitor (EXO-1) to carry out a comprehensive water temperature monitoring of the reservoir area. The measurement started in 2017, and the measurement time was from August to November 2017 and from April to November 2018. There were 13 measurement sites including the dam-front of Daheiting Reservoir, the central area of the reservoir, the estuary of Panjiahe River, the estuary of Sahe River at the dam-tail (to obtain data about the planar and vertical distribution of water temperature in the reservoir, a network of measurement sites was deployed in the reservoir since June 2018, and a total of 35 measuring lines were arranged). Figure 1 shows the locations of the measurement sites.

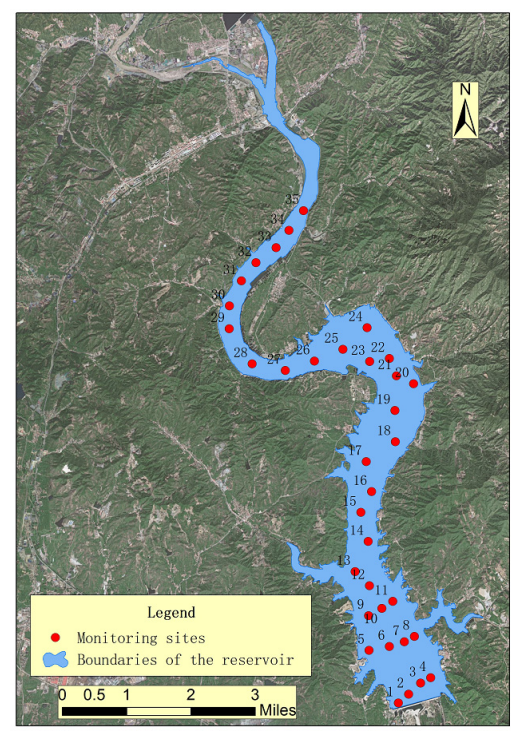

Networked measurement sites

Figure 1. Locations of water temperature measuring sites in Daheiting Reservoir 


\section{Results and discussion}

\subsection{Temporal evolution of the anoxic zone in Daheiting Reservoir}

The vertical water temperature data monitored at the damfront from August 2017 to November 2018 were charted to analyze the temporal change patterns of thermal stratification at the dam-front of Daheiting Reservoir (Figure 2).

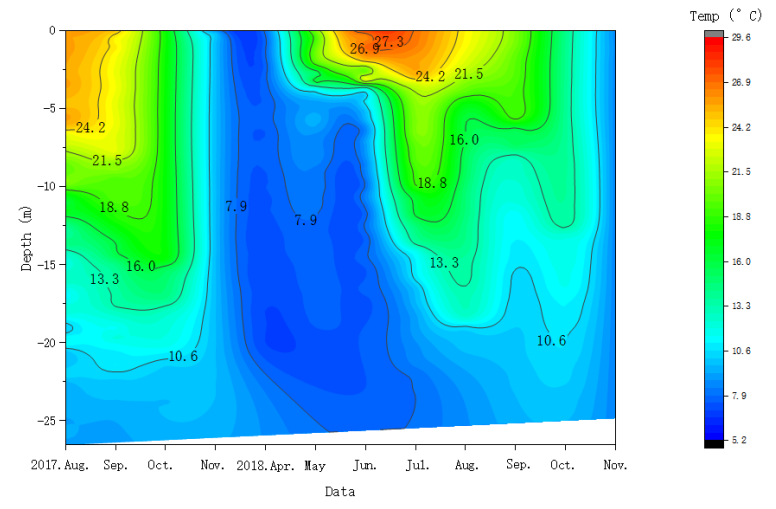

Figure 2. Temporal changes in the vertical water temperature structure of Daheiting Reservoir

As Figure 2 shows, Daheiting Reservoir is a typical dimictic reservoir. It presents significant patterns of annual evolution of thermal stratification. The water at the dam-front of the reservoir has two states: mixture and layering. Thermal stratification occurs from May to September, while mixture occurs in April and November. After the freezing-up period, the water at the dam-front is in a mixing state, and with the increase of the air temperature, the temperature of water at the surface increases as well, leading to a larger temperature difference between the surface and the bottom of the reservoir, which results in significant thermal stratification in May. The thermal stratification enters a stable state from

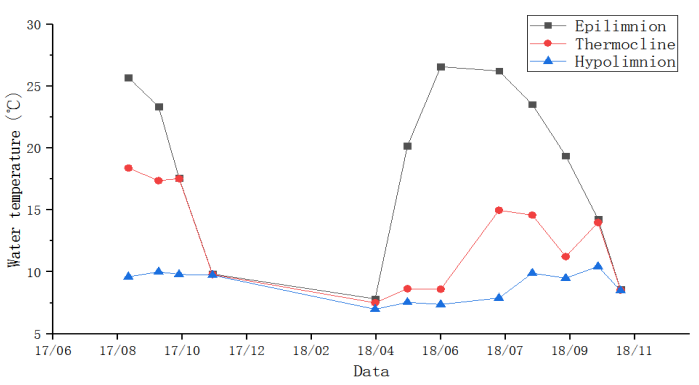

a. temporal changes of water temperature in Daheiting Reservoir
June to August. From September to October, as the air temperature drops, the water temperature decreases as well, leading to a narrower gap of temperature between the surface and the bottom of the reservoir but more active mixture along the vertical direction. In this period, the water temperature structure shifts from the layered structure to the mixture structure, thermal stratification starts to disappear, which disappears completely and shifts to vertical mixture in November. It should be noted that compared with the period from July to August in 2017, in the same period in 2018 , the reservoir performed massive discharge of water, which led to significant flow of water and intensive mixture of water along the vertical direction, disturbing the stratified structure of water temperature in the reservoir. In this period, the thickness of the thermocline increased, the water temperature in the hypolimnion rose, the vertical difference of water temperature declined, and the thermal stratification effect became less significant.

Figure 3a shows the water temperature changes at the epilimnion, thermocline and hypolimnion of Daheiting Reservoir throughout a year, and Figure $3 b$ shows the stability of thermal stratification in different months at the dam-front. As these figures show, the surface water temperature shows significant changes within the year, increasing from $7.83^{\circ} \mathrm{C}$ in April to $26.57^{\circ} \mathrm{C}$ in June, an increase by $18.74^{\circ} \mathrm{C}$, which indicates the significant impact of seasonal changes and the air temperature on the water temperature at the epilimnion of the reservoir. The water temperature at the hypolimnion, however, showed smaller changes; it rose from $6.99^{\circ} \mathrm{C}$ in April to $10.45^{\circ} \mathrm{C}$ in October, an increase by about $3^{\circ} \mathrm{C}$, which suggests little impact of the meteorological conditions on the water temperature at the hypolimnion. During the full mixture period, the stability of thermal stratification decreased, and after the thermal stratification began, the stability index rose, which reached the maximum at 409.7 in June 2018. Then, as thermal stratification disappeared, the stability of thermal stratification witnessed a significant drop.

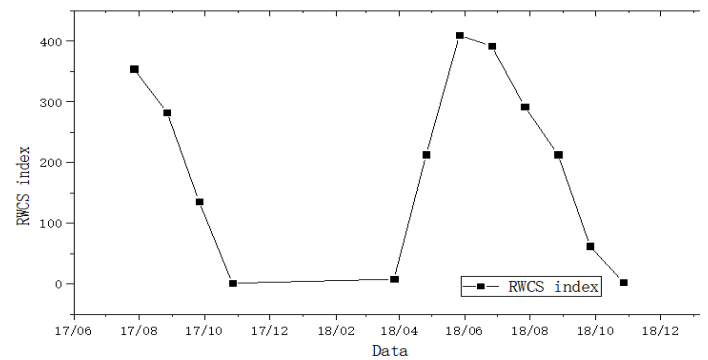

b. temporal changes of stability of thermal stratification in Daheiting Reservoir

Figure 3. Temporal changes in the surface-bottom temperature difference and stability index in Daheiting Reservoir

\subsection{Spatial evolution characteristics of thermal stratification in Daheiting Reservoir}

To analyze the spatial evolution features of thermal stratification of the reservoir, the water temperature measurement results along the reservoir were sorted to prepare vertical isopleth diagram of the measuring section of the reservoir by month. Figure 4 shows the distribution of water temperature along the reservoir by month.

As Figure 4 shows, the spatial evolution of thermal stratification presents a tangible pattern. In August 2017, the thermal stratification stretches $14 \mathrm{~km}$ from the damfront to the dam tail, covering a wide range. Beyond 14 
$\mathrm{km}$, the water depth decreases and presents more features of water channels, and the thermal stratification effect disappears. In September, as thermal stratification alleviated, the stretch decreased to $10 \mathrm{~km}$, which was shorter than in August. Thermal stratification decreased further in October, with the reach shrinking to $8 \mathrm{~km}$. In November, the reservoir entered a mixing state and no thermal stratification was found. After it moved to May 2018, thermal stratification re-occurred, reaching a stretch of $14 \sim 16 \mathrm{~km}$, and it lasted to June. In July and August, under the impact of water discharge, the thermal stratification was disturbed and reached a smaller scope, and the reach of the stratification decreased to $6 \sim 9 \mathrm{~km}$. Thermal stratification recovered to a degree, and the spatial reach increased again to $14 \mathrm{~km}$. After October, thermal stratification recessed, with its spatial reach shrunk to none.

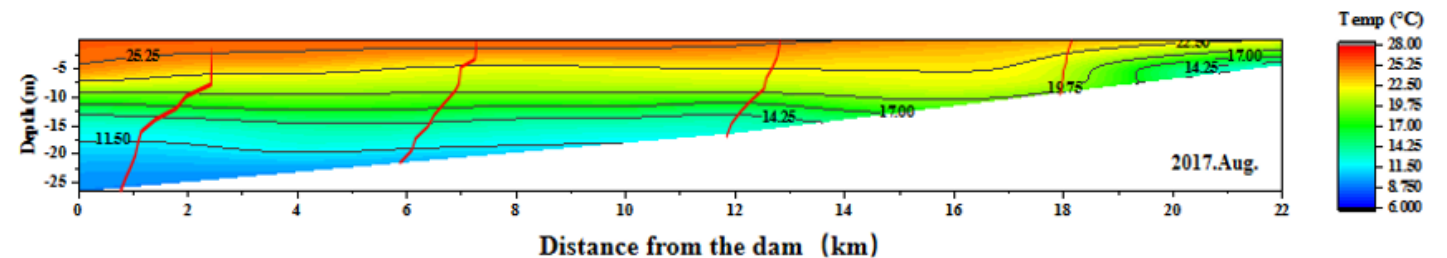

Water temperature structure along the reservoir in August 2017

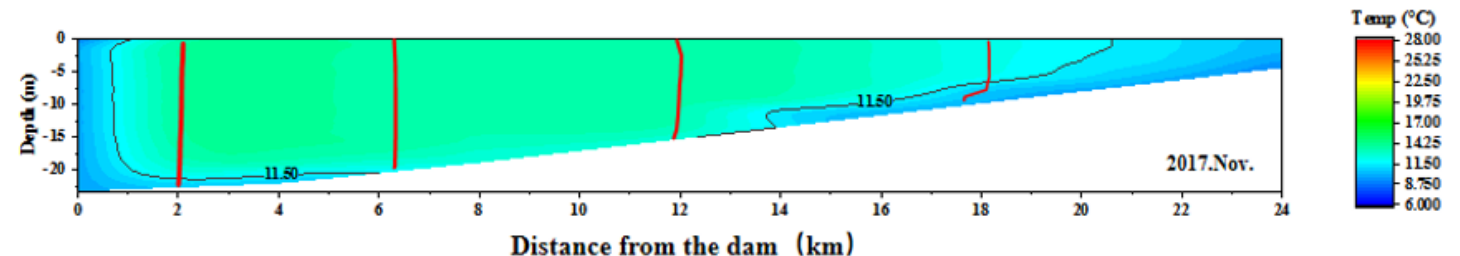

Water temperature structure along the reservoir in November 2017

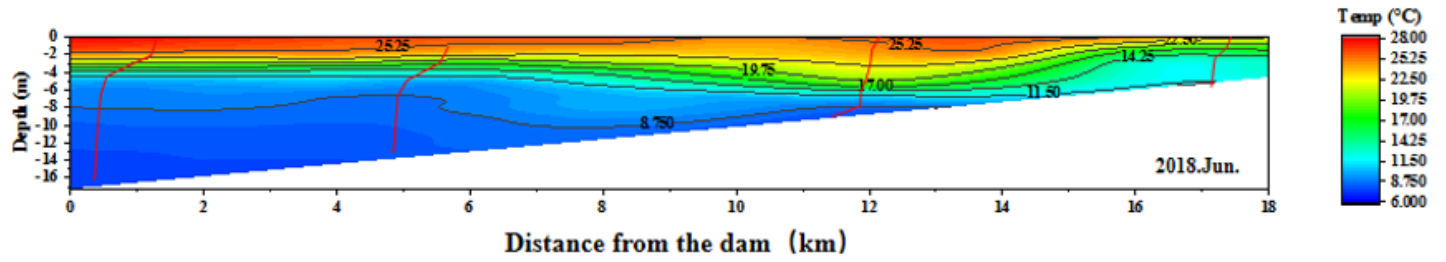

Water temperature structure along the reservoir in June 2018

Figure 4. Water temperature structure characteristics along the reservoir

\subsection{Driving factors for thermal stratification in Daheiting Reservoir}

(1) Response relations between the thermal stratification and air temperature in Daheiting Reservoir

Figure 5 shows the relations between the different layers of water and the air temperature. As the figure shows, the air temperature in the area of Daheiting Reservoir showed large differences across the year, and the water temperature changes at the epilimnion "followed" or partly "followed" this pattern; the water temperature in the thermocline also showed a similar pattern, but the changes were less significant; while the water temperature at the hypolimnion was largely not correlated to the air temperature.

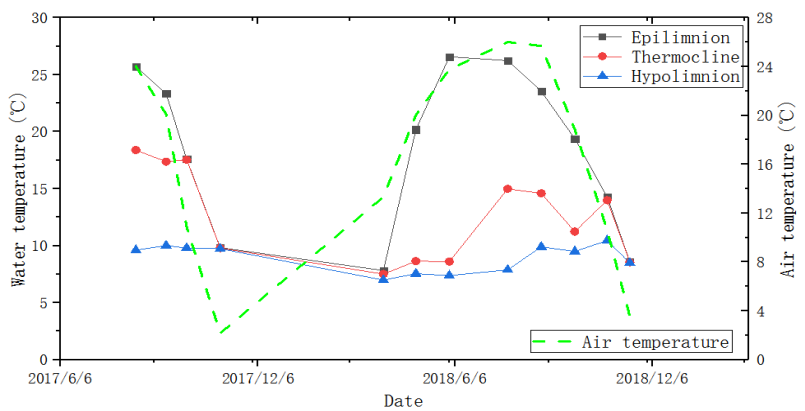

Figure 5. Correlation between water temperature at different layers of the reservoir and the air temperature

Figure 6 shows the analysis results of the correlation between the water temperature at different layers of the reservoir with the air temperature. As Figure 6 shows, the water temperature at the epilimnion is strongly correlated to the air temperature (Pearson correlation coefficient $=$ $0.898, \mathrm{P}<0.001$ ), while no tangible correlation is observed between the water temperature at the hypolimnion and the air temperature. In fact, it is the difference in the correlation between the air temperature and the water temperature at different layers of the reservoir that leads to the thermal stratification. When the air temperature rises, the water temperature at the epilimnion rises as well, 
while the water temperature at the hypolimnion is largely unaffected, leading to a larger gap in the temperature of

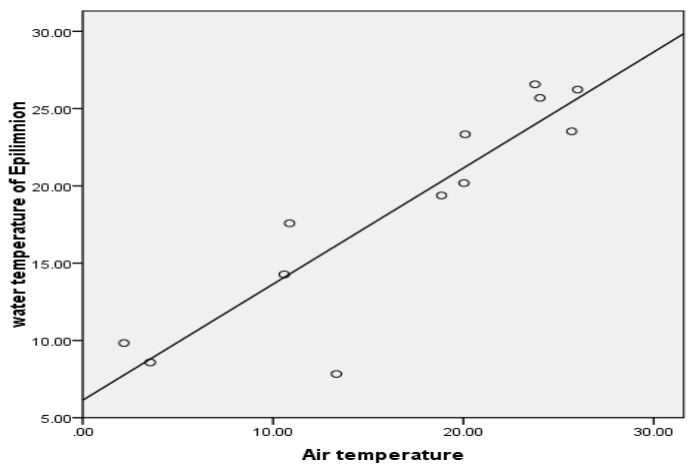

a. Correlation between air temperature and the water temperature at the epilimnion the water on the surface and that at the bottom of the reservoir.

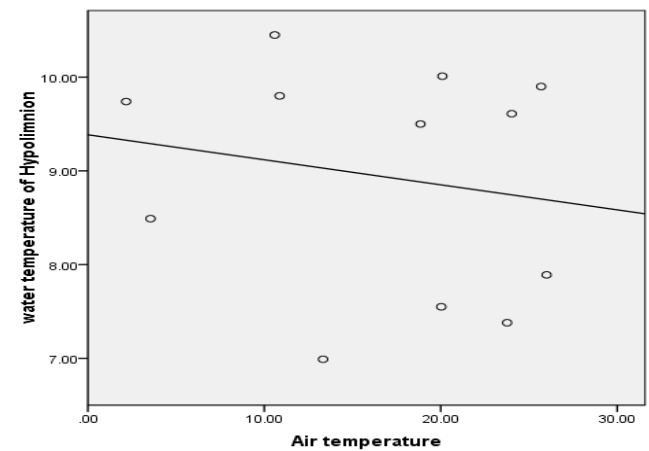

b. Correlation between air temperature and the water temperature at the hypolimnion

Figure 6. Correlation between air temperature and water temperature in Daheiting Reservoir

(2) Response relation between thermal stratification in Daheiting Reservoir and the wind speed

With the data of the measured wind speed, the thermal stratification stability and the water mixture depth in the reservoir, the correlation between thermal stability and the wind speed was identified, as shown in Figure 7. The wind speed and the thermal stratification in the reservoir shows significant negative correlation (Pearson correlation coefficient $=-0.842, \mathrm{P}=0.001)$. The thermal stability decreases as the wind speed increases. During the early stage of thermal stratification, the wind disturbance in

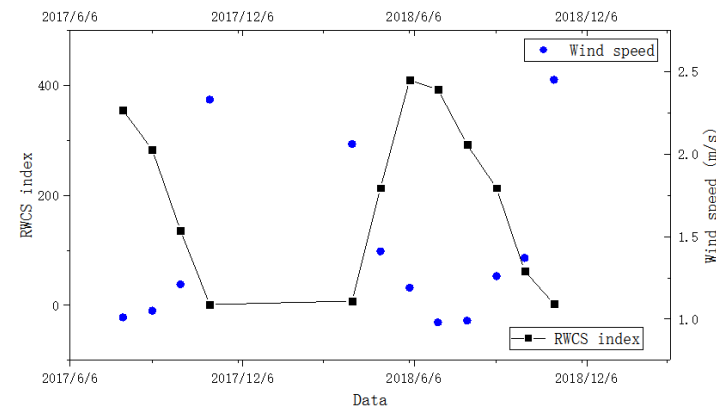

a. Changes in wind speed and thermal stability index spring led to the formation of an epilimnion layer on the surface of the reservoir; later, when the thermal stratification entered a stable state, a small wind speed ensured stability of the epilimnion layer and the thermocline layer below; in autumn when the water tensity at the hypolimnion decreased with the dropping air temperature, strong wind increased vertical mixture of water in the reservoir and boosted temperature exchange, which finally resulted in the disappearance of thermal stratification in November.

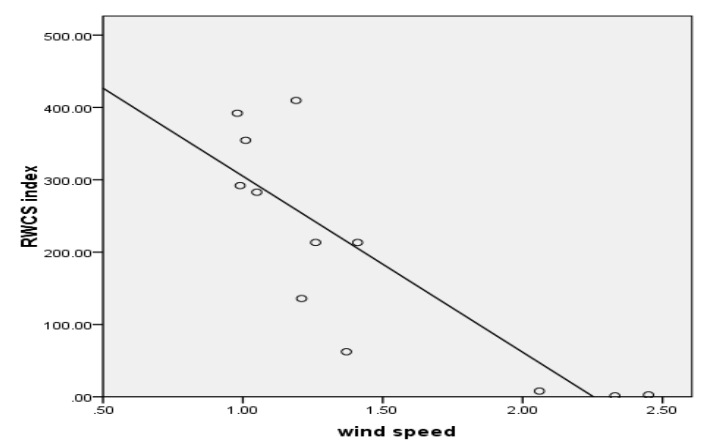

b. Correlation between wind speed and the thermal stability index

Figure 7. Relationship between wind speed and thermal stability index in the reservoir

(3) Correlation between hydrodynamic conditions and thermal stratification in Daheiting Reservoir

One distinction between the reservoir and lakes is the hydrodynamic conditions. Lakes often feature a large area and see no significant changes in the hydrodynamic conditions or shocks from water inflow across the year. In reservoirs, however, there are regular inflows or outflows of water in a given time period of time, which result in changes in the thermal stratification structure.

Figure 8 shows the discharge volume of water from 2017 to 2018 in Daheiting Reservoir. As the figure shows, the discharge volume changed significantly within the year, with the maximum monthly discharge increasing from $78.2 \mathrm{~m}^{3} / \mathrm{s}$ in 2017 to $274 \mathrm{~m}^{3} / \mathrm{s}$ in 2018 , a 3.5 -fold difference. Such significant differences within the year and across years had significant impacts on the thermal stratification in the reservoir.

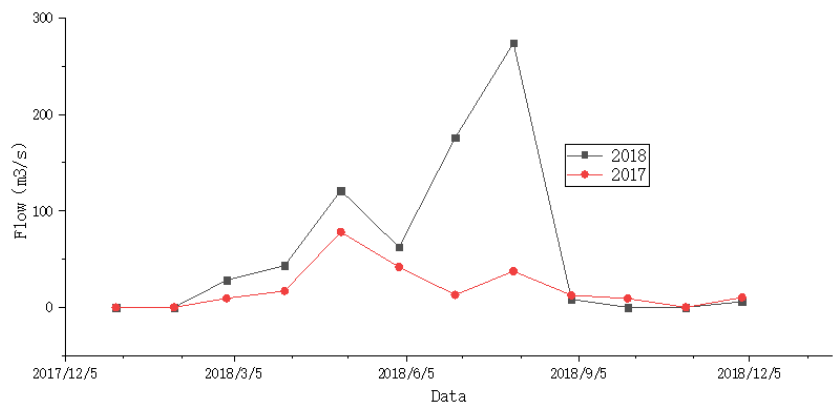

Figure 8. Comparison of monthly discharge volume in 2017 and 2018 in Daheiting Reservoir 
The data in August 2017 and August 2018 were compared to explore the impact of hydrodynamic factors on thermal stratification in the reservoir. First, other influencing factors on thermal stratification in these two months except the discharge volume are presented in Table 1. As the table shows, the key factors including the meteorological conditions and water depth that affect the thermal stratification in August in 2017 and 2018 do not show much difference. Due to the differences in water discharge in August between these two years, thermal stratification varied. Figure 9 shows the vertical water temperature layers in August of 2017 and 2018.

Table 1 Comparison of factors affecting thermal stratification of Daheiting Reservoir except water discharge in August 2017 and 2018

\begin{tabular}{lllll}
\hline & $\begin{array}{l}\text { Average } \\
\text { monthly } \\
\text { temperature } \\
\left({ }^{\circ} \mathrm{C}\right)\end{array}$ & $\begin{array}{l}\text { Average } \\
\text { monthly } \\
\text { wind } \\
\text { speed } \\
(\mathrm{m} / \mathrm{s})\end{array}$ & $\begin{array}{l}\text { Average } \\
\text { monthly } \\
\text { water } \\
\text { level }(\mathrm{m})\end{array}$ & $\begin{array}{l}\text { Average } \\
\text { monthly } \\
\text { water } \\
\text { depth } \\
(\mathrm{m})\end{array}$ \\
\hline $\begin{array}{l}\text { August } \\
2017\end{array}$ & 24.02 & 1.01 & 130.5 & 22.5 \\
\hline $\begin{array}{l}\text { August } \\
2018\end{array}$ & 25.69 & 0.99 & 130.4 & 22.4 \\
\hline
\end{tabular}

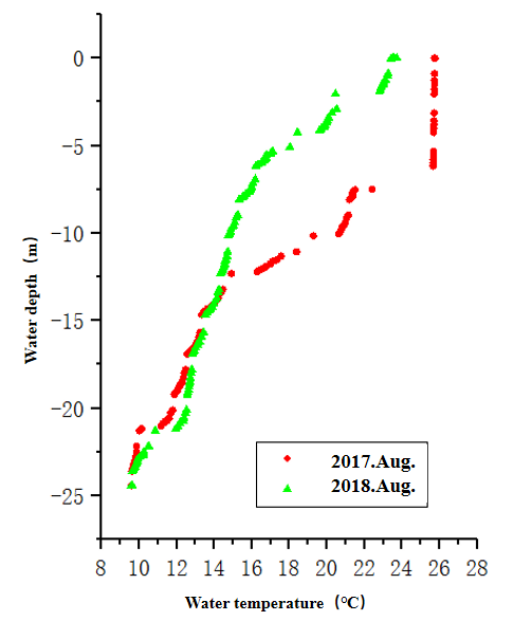

Figure 9. Comparison of water temperature at the dam-front in August 2017 and August 2018 in Daheiting Reservoir

As the water discharge data show, the discharge volume witnessed a sharp increase in Daheiting Reservoir from 2017 to 2018, with the maximum daily discharge surging from $58.9 \mathrm{~m}^{3} / \mathrm{s}$ in August 2017 to $795 \mathrm{~m}^{3} / \mathrm{s}$ in August 2018. This increase in discharge led to significant impacts on the water temperature structure at the damfront. As Figure 9 shows, with other factors being equal, the thermal stratification structure showed significant difference between August 2017 and August 2018. Specifically, in August 2017, an obvious three-layer structure of water temperature was observed in the reservoir, while in August 2018, due to large discharge of water, the vertical mixture of water in the epilimnion and the thermocline increased, the water temperature above the hypolimnion showed a general decrease, the temperature gradient between the epilimnion and the thermocline largely disappeared, and the thermal stratification at the dam-front was fundamentally disturbed. Analyses above revealed that the hydrodynamic conditions, as a specific contributor to thermal stratification in reservoirs, could change the thermal stratification in reservoirs when other factors were kept the same. Therefore, the hydrological condition accounts for a major contributor to the thermal stratification in the reservoir.

\section{Conclusion}

(1) Taking Daheiting Reservoir, the source reservoir of the water diversion project from Luanhe River to Tianjin City as the research object, this study performed long-series and full-space water temperature measurement from the front to the tail of the dam of the reservoir. With the measured data, the spatio-temporal changes of water temperature structure in the reservoir were analyzed. In combination with the measured meteorological and discharge data, the driving factors of thermal stratification in the reservoir was explored.

(2) The air temperature decides the seasonal change pattern of the water temperature at the epilimnion of the reservoir. Besides, due to the uneven transfer of solar radiation along the vertical direction of the water in the reservoir, the changes in the air temperature will lead to a high gradient of temperature and density of water along the vertical direction, which accounts for the root cause for thermal stratification in the reservoir. The decrease of air temperature significantly decreases the difference of water temperature and density along the vertical direction, leading to significant drops in the thermal stability of the water and finally resulting in full mixture. Thus, the air temperature is a driving factor of thermal stratification in Daheiting Reservoir.

(3) Wind disturbance is an auxiliary factor that contributes to formation and disappearance of thermal stratification in the reservoir. During thermal stratification, the wind boosts mixture of water on the surface of the reservoir, resulting in the epilimnion; meanwhile, as the thickness of the epilimnion increases, the thermal stratification enters a stable state. When thermal stratification recesses, the wind accelerates mixture of water that has already experienced a drop in thermal stability along the vertical direction, which contributes to the disappearance of thermal stratification.

(4) Hydrodynamic conditions, as an influencing factor unique to reservoirs, directly affects the distribution of the thermal layers along the vertical direction in the reservoir when other factors are kept unchanged. The shock from massive discharge of water disturbs the structure of the epilimnion and the thermocline, changing the thermal stratification structure in the reservoir. Thus, hydrodynamic conditions also account for a major contributor to thermal stratification in the reservoir.

(5) In sum, air temperature, wind speed, and hydrodynamic conditions are the major driving factors to the formation and distribution of thermal stratification in Daheiting Reservoir. Among these factors, the air temperature is the fundamental condition for formation of thermal stratification, the wind speed is an auxiliary factor 
that promotes formation and disappearance of thermal stratification, and the hydrodynamic conditions are the major disturbing factor that affects the thermal stratification structure. All these factors have acted together to affect the pattern and evolution of thermal stratification in Daheiting Reservoir.

\section{Author information:}

Liu Chang (1977 -), senior engineer engaged in research on the environmental impact of hydropower engineering. Email: liuch@iwhr.com

\section{Acknowledgement}

Acceptance date:

Funding: this study is funded by the National Key Research and Development Program (2016YFC0401701, 2018YFC0407601), the National Natural Science Foundation of China (51679256), The Innovation Team Program of Ecological Guarantee and Regulation Technology for Key Water Conservancy Projects (WE0145B592017), and China Institute of Water Resources and Hydropower Research (WE0163A052018, WE0163A042018, WE0145B422019, HTWE0202A242016).

\section{References}

1. BERTRAM BOEHRER, MARTIN SCHULTZE. Stratification of lakes [J]. Reviews of Geophysics, 2008, 46 (2): 620-628.

2. HUTCHINSON, G. E. A Treatise on Limnology, Vol. 1: Geography, Physics and Chemistry [M]. Wiley, New York, 1957,1015 pp.

3. BO-PING HAN, JOAN ARMENGOL, JUAN CARLOS, et al. The thermal structure of Sau Reservoir (NE: Spain): a simulation approach[J]. Ecological Modelling 125 (2000) 109-122.

4. CHAPMAN P J, KAY P, MITCHELLl G, et al. Surface water quality. In: Holden J (Ed). Water Resources: An Integrated Approach [A]. London, United Kingdom: Routledge, 2014. 79-122.

5. FORD, D.E., Reservoir transport processes. In: Thornton, K.W., Kimmel, B.L., Payne, F.E. (Eds.), Reservoir Limnology: Ecological Perspectives[M]. Wiley, New York, 1990. pp.15-41.

6. STRASKRABA, M., Limnological basis for modelling reservoir ecosystems. In: Ackerman W.C., White F.G., Worthinton, E.B. (Eds.), Man-made Lakes: their Problems and Environmental Effects[M]. American Geophysical Union, Washington, DC, Geophys. Monogr. 1973. 17, 517-535

7. RIERA J.L, JAUME D.,MANUEL J.et al.Patterns of variation in the limnology of Spanish reservoirs[J].a regional study. Limnetica 8, 1992.111-123.

8. STRASKRABA, M., TUNDISI, J.G., DUNCAN, A.State-of-theart of resevoir limnology and water quality management. In: Straskraba, M., Tundisi, J.G., Duncan, A. (Eds.), Comparitive Resevoir Limnology and Water Quality Management [M]. Kluwer Academic Publishers, 1993.pp. 213-288.

9. AREMENGOL, J., CRESPON, M., MORGUI, J.A.. Phosphorus budget and forms of phosphorus in the Sau reservoir sediment: an interpretation of the limnological record[J]. Hydrobiologia 1986.143, 331-336.

10. HOCKING, G., STRASKRABA, M., An analysis of the effect of an upstream reservoir using a mathematical model of [1]reservoir hydrodynamics[J]. Wat. Res. Tech. 1994. 30, 91-98.

11. HORNE AJ, GOLDMAN R Limnology 2nd ed[M]. McGraw-Hill, New York .1994.

12. IMBERGER J., HAMBLIN PF. Dynamics of lakes, reservoirs and cooling ponds[J]. Ann Rev Fluid Mech 1982, 14: 153-187.

13. IMBERGER J, PATTERSON J.C. Physical Limnology[J]. Advances in Applied Mechanics.1990.27: 303-455 International Lake Environment Committee (1990) Lake Toba. NEWSLETTER 14

14. HONDZO M, STEFAN HG.Long-term Lake Water Quality Predictors[J]. Water Res (1996)30: 2835 2852.

15. WILHELM SCHMIDT, Über die Temperatur- und Stabilitätsverhältnisse von Seens[J].Geografiska Annaler, 1928, Vol. 10 pp. 145-177.

16. GORHAM E, BOYCE FM. Influence of lake surface area and depth upon thermal stratification and the depth of the summer thermocline[J]. 1989.J Great Lakes Res 15:233-45.

17. FEE EJ, HECKY RE, KASIAN SEM. Cruikshank DR. Effects of lake size, water clarity, and climatic variability on mixing depths in Canadian shield lakes[J]. Limnol Oceanogr.1996. 41:912-20.

18. SNUCINS E, GUNN J. Interannual variation in the thermal structure of clear and coloured lakes. $[\mathrm{J}]$ Limnol Oceanogr .2000.45: 1639-46. 